\title{
The psychological features of patellofemoral pain: a systematic review
}

\author{
Liam R Maclachlan, Natalie J Collins, Mark L G Matthews, Paul W Hodges, \\ Bill Vicenzino
}

- Additional material is published online only. To view please visit the journal online (http://dx.doi.org/10.1136/ bjsports-2016-096705).

The University of Queensland, School of Health and Rehabilitation Sciences, Brisbane, Australia

\section{Correspondence to} Bill Vicenzino, The University of Queensland, School of Health and Rehabilitation Sciences, St Lucia, Brisbane, QLD 4072, Australia ; b.vicenzino@uq. edu.au

Accepted 3 January 2017 Published Online First 20 March 2017
CrossMark

To cite: Maclachlan LR, Collins NJ, Matthews MLG, et al. Br J Sports Med 2017:51:732-742.

\section{ABSTRACT}

Background Patellofemoral pain (PFP) is prevalent in adolescence and adulthood and often persists. In contrast to other persistent musculoskeletal conditions, for which non-physical, psychological features are implicated, PFP remains largely conceptualised in mechanical terms.

Aims To (1) identify whether the psychological characteristics of individuals with PFP differs from asymptomatic controls and (2) evaluate the correlations between psychological characteristics and PFP severity.

Study design Systematic review

Methods A systematic review of the literature was conducted according to PRISMA guidelines. The Epidemiological Appraisal Instrument was used to evaluate quality. Studies measuring psychological constructs with patient-reported measures were included. Standardised mean differences were calculated and supported by narrative synthesis.

Results Twenty-five studies were eligible. Quality results ranged from $28.3 \%$ to $61.7 \%$. Psychological constructs were reported under four groupings: mental health, cognitive factors, behavioural factors and other factors. There is limited evidence of mental health and cognitive differences in some individuals with PFP. Features demonstrating linear correlations with pain and physical function included anxiety/depression, catastrophising, praying and hoping and pain-related fear.

Conclusions Anxiety, depression, catastrophising and fear of movement may be elevated in individuals with PFP and correlate with pain and reduced physical function. These results derive from a limited number of studies. Future research should aim to evaluate if and how psychological factors contribute to PFP.

Clinical relevance Patients are likely to benefit from clinician vigilance to the presence of psychological factors.

\section{INTRODUCTION}

Patellofemoral pain (PFP) is a prevalent musculoskeletal condition ${ }^{12}$ that presents as an anterior knee pain provoked by physical activities that load/stress the patellofemoral joint. ${ }^{34}$ It is heterogeneous, presents throughout the lifespan ${ }^{5}$ and is often persistent. ${ }^{6}$ Research shows that $40 \%$ to $57 \%$ of those receiving evidence-based treatments ${ }^{7}$ experience unfavourable long-term outcomes. ${ }^{8} 9$ Persistent PFP and poor long-term outcomes may impact negatively on social engagement and participation in physical activities such as sports and occupational tasks. ${ }^{10}$

Growing evidence suggests that non-physical, psychological features play a role in persistent musculoskeletal pain. Factors such as pain-related fear, anxiety, depression, catastrophising and self-efficacy have been associated with pain ${ }^{11}$ and disability. ${ }^{12}{ }^{13}$ They have also been identified as barriers to recovery ${ }^{14}$ and as factors that limit the potential for improvement with rehabilitation. ${ }^{15}$ As a result, presence of these features is often factored into treatment decision-making for other musculoskeletal conditions. ${ }^{16-19}$

As a persistent musculoskeletal condition that is no longer considered self-limiting, ${ }^{6920}$ PFP may also be characterised by the coexistence of physical and non-physical features. If non-physical features can influence the outcomes of physical interventions, then further investigation into the non-physical features of PFP is essential. Ultimately, a better understanding of the non-physical features of PFP stands to enhance the outcomes of currently used physical interventions and expose other features at which management may be targeted or which may influence how a treatment is applied.

The aims of this systematic review were to (1) identify whether the psychological characteristics of individuals with PFP differ from that of asymptomatic controls and (2) evaluate the correlation between psychological characteristics and measures of pain and physical function in individuals with PFP.

\section{METHODS}

The systematic review protocol was developed in accordance with the 2009 Preferred Reporting Items for Systematic reviews and Meta-Analyses (PRISMA) statement ${ }^{21}$ and prospectively registered with PROSPERO (Registration: CRD42016036379).

\section{Search strategy and data sources}

A search using 'patellofemoral pain' OR 'patellofemoral pain syndrome' OR 'anterior knee pain' OR 'chondromalacia patellae' was conducted. It was expected that this unrefined approach would yield high returns and would reduce the chance of lesser known psychological measurements being missed.

Eight electronic databases were searched (Cinahl, Cochrane library, EMBASE, MEDLINE, PubMed, PEDro, PsycINFO, Scopus). Databases were searched by the first author (LM), with the final search conducted on the 13th of January 2016. Electronic results were followed by reference list checks and author searches. Published reports, conference abstracts and reference lists were also perused.

\section{Eligibility criteria}

As an epidemiologically based review, the scope of included studies was purposefully broad. To be 
included, studies had to measure at least one psychological variable using a patient-reported format in a cohort of individuals with PFP. Studies were included that clearly defined diagnostic criteria for PFP, the diagnostician or described the condition as 'PFP'. For studies that recruited mixed (symptomatic) populations, we included those for which data pertaining solely to individuals with PFP could be extracted.

Studies were excluded if they were case studies, published abstracts, non-published studies (eg, graduate theses) or non-primary literature (eg, systematic and narrative reviews).

\section{Study selection}

Studies identified in database searches were exported to EndNote (X7.2.1). Two reviewers (LM, MM) independently evaluated titles and abstracts, and then full texts. Consensus meetings were held at each stage to determine progression to the next stage, and discrepancies were resolved by a third author (BV).

\section{Data extraction}

Data extraction was completed independently by two reviewers (LM and MM) using a standardised spreadsheet. Data of interest included: (1) participant characteristics-source, sex, age, body mass index (BMI), education level, employment status, smoking status and activity levels; (2) PFP characteristics-diagnostic criteria, pain measure used, pain duration, pain severity, location of pain; and (3) psychological factors: measures used and results.

\section{Methodological quality assessment}

The methodological quality of each study was assessed independently by two reviewers (LM, NC), one of who (NC) was blinded to journal, study title, authors and affiliations, using the Epidemiological Appraisal Instrument (EAI). ${ }^{22}$ As a general purpose appraisal instrument, the EAI can be used to evaluate intervention, cohort, case-control and cross-sectional studies. With a total of 43 questions grouped into five sections, the EAI considers: (1) reporting; (2) participant/record selection; (3) measurement quality; (4) data analysis; and (5) generalisation of results. Items are answered 'yes' (2), 'partial' (1), 'no' (0), 'unable to determine' (0) or, depending on study design, 'not applicable'. To answer questions pertaining to covariates and cofounders, the review team selected, a priori, specific factors that the World Health Organisation has recognised as risks to mental health..$^{23}$ These factors were age, sex, BMI, pain severity and duration, smoking, employment status, education level and activity level. Summary scores were expressed as a proportion of all items that were applicable. Methodological quality criteria were graded specific to the research question for this systematic review rather than for the general quality of each study and its original purpose. Thus, methodological quality scores presented are specific to this review and should not be interpreted in different contexts. In the absence of an absolute external reference, quartiles were used to express final quality rank. The first quartile (Q1) represents the lowest scoring papers and the fourth quartile (Q4) the highest.

\section{Data synthesis}

Inter-rater reliability between methodological quality assessors was calculated in STATA V.14.0 and presented as a $\kappa$ Statistic. Inter-rater reliability was considered as poor $(<0.00)$, slight $(0.00-0.2)$, fair (0.21-0.4), moderate (0.41-0.6), substantial $(0.61-0.8)$ or almost perfect $(0.81-1.0)^{24}$ Psychological findings are presented under two headings that directly fulfil the review's aims: (1) psychological characteristics of people with PFP and
(2) correlations between psychological factors, PFP and physical function. Standardised mean differences (SMD) and 95\% CI were calculated using Review Manager (RevMan) V.5.3. The SMD results from negatively orientated measures (ones where a lower score represents poorer psychological health) were inverted so that all positive SMD meant the same thing; that is, higher positive SMD indicated poorer psychological health in the PFP group. An SMD greater or equal to 0.2 was considered small, greater or equal to 0.50 , medium and greater or equal to 0.80 , large ${ }^{25}$ Corresponding correlation coefficient indexes were $0.10,0.30$ and 0.50 , respectively. ${ }^{25}$ When only frequency data were available, risk ratios were calculated using RevMan V.5.3. The above descriptives were used where meta-analyses were not possible. Where effect sizes could not be calculated (eg, lack of control group), raw data were tabulated and presented graphically. Electronic searches were conducted to obtain normative data for comparisons.

\section{RESULTS}

\section{Study selection and design}

The search yielded 10617 studies. After removal of duplicates, there were 6772 studies for title and abstract perusal. Fifty studies were eligible for full-text review, of which 25 met the eligibility criteria and were included (figure 1). These, by design, comprised 16 case series and nine cohort studies. Comparative data were available in five instances, correlative in nine, while the remaining 11 provided descriptive data (table 1).

\section{Methodological quality assessment}

Online supplementary file 1 contains full-quality appraisal results for all studies (itemised marking, the total percentage each study scored and an overall percentage of studies that addressed each criteria) along with a quartile table. With 879 agreed responses from 1075 items, the overall agreement between the two assessors was substantial $(\kappa=0.75) .{ }^{24}$ The median methodological quality percentage score was $45.2 \%$ (IQR 37.1 to 51.5 ) the minimum was $28.3 \%$ and the maximum was $61.7 \%$. Seven studies, scoring between $28.3 \%$ and $37.1 \%$ fell in the 1 st quartile (Q1); six studies (score $40 \%$ to $45.2 \%$ ) fell in the 2nd quartile (Q2); seven studies (score $46.7 \%$ to $51.5 \%$ ) fell in the 3 rd quartile (Q3); and five studies (score $51.6 \%$ to $61.7 \%$ ) fell in the 4 th quartile (Q4]. The reliability and validity of the psychological measures used were described and referenced in $12 \%(3 / 25)$ and $28 \%(7 / 25)$ of studies, respectively. When performing data analyses, 76\% (19/25) of studies did not adjust for intrinsic factors (age, gender, BMI) and $88 \%(22 / 25)$ did not adjust for extrinsic factors (smoking status, employment status, educational level, activity level). Five per cent $(1 / 20)$ of studies reported psychological findings by PFP levels (severity and/or duration) and 4\% (1/25) of studies reported psychological findings by age, sex, BMI, smoking, employment status, education level, activity level) subgroups.

\section{Participant characteristics}

Table 1 presents participant characteristics for all included studies. Across all studies, there were 1357 participants with PFP (891 women: 66\%), with the mean (SD) age ranging from 14.1 (1.38) to 46.6 (10.8) years old. Participants were sourced from clinical sites, ${ }^{26-42}$ athletics clubs and exercise programmes ${ }^{43}$ ${ }^{44}$ and population-based cohorts. ${ }^{45}{ }^{46}$ Five studies did not report participant sources.

The 349 healthy controls (168 women: 48\%) came from student cohorts ${ }^{44-47}$ or from the local community. ${ }^{48}$ One study 


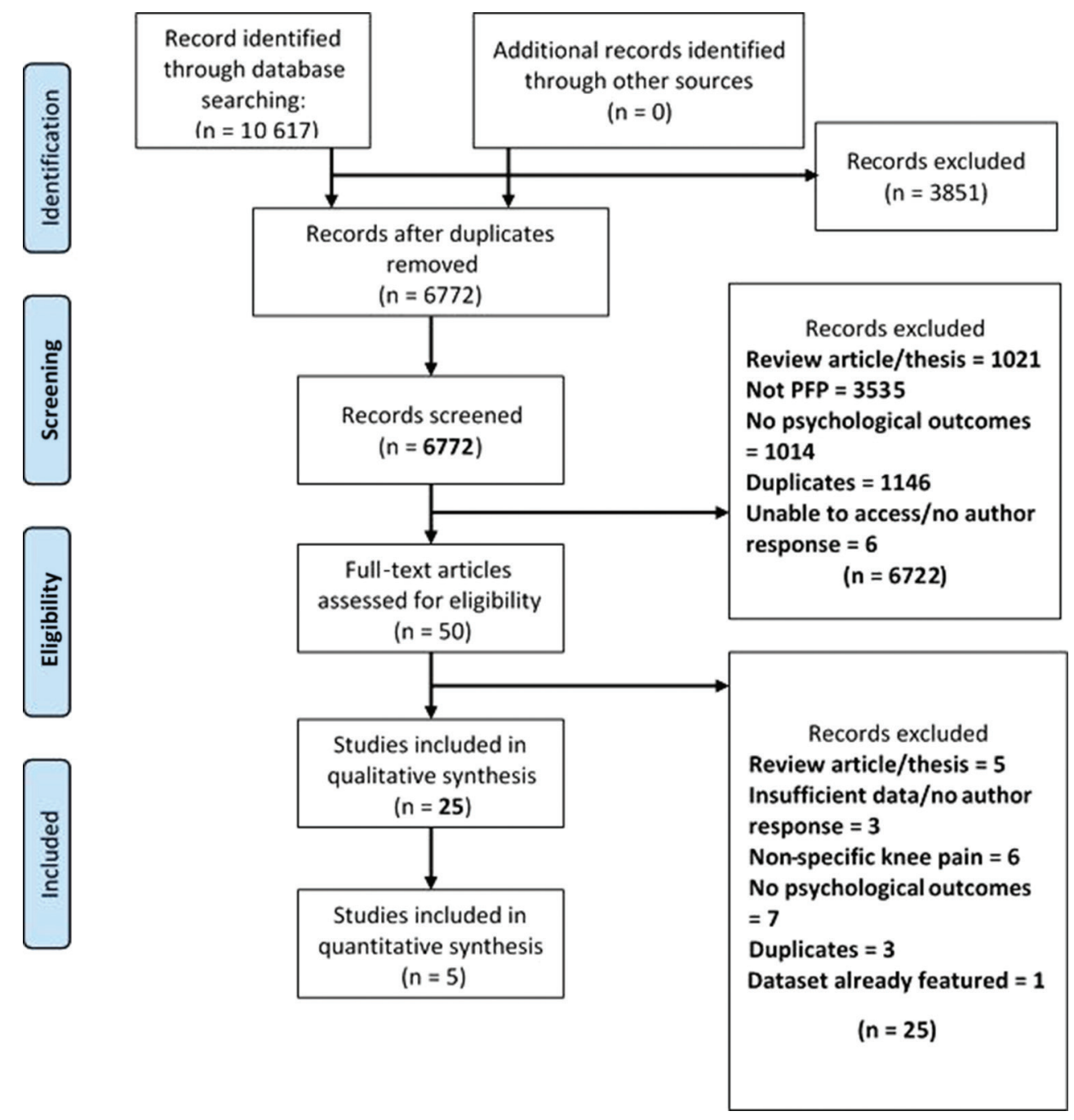

Figure 1 Eligibility flow diagram.

did not state their control source. ${ }^{27}$ Typically, the control characteristics were matched to corresponding PFP groups and are presented in table 1 .

\section{PFP characteristics}

Details relating to PFP characteristics, including duration, severity and measurement tools are presented in table 1. Criteria used to define/diagnose PFP along with the diagnosing health professional were provided in 14 studies. ${ }^{27} 3134-38414244-48$ In five studies, the diagnostic criteria alone were described without the diagnostician. ${ }^{2632404950}$ A further six studies named the diagnosing health professional but not the diagnostic criteria. ${ }^{29} 30333943$

Pain was most commonly measured with a Visual Analogue Scale, ${ }^{29} 3042454648-50$ followed by a Numerical Rating Scale, ${ }^{33} 36-39$ ${ }^{41}$ then the Western Ontario and McMaster Universities Arthritis Index pain subscale ${ }^{27} 32$ and the Knee Injury and Osteoarthritis Outcome Score (KOOS) pain subscale. ${ }^{45} 46$ Pain duration ranged from a minimum of 1 month $^{36}$ to 8 years. ${ }^{47}$

Physical function was most commonly measured with the Kujala Patellofemoral Score, ${ }^{26} 28354350$ Lysholm Knee Scoring Scale, ${ }^{293033}$ Activities of Daily Living Scale of the Knee Outcome Survey, ${ }^{36} 37$ Modified Functional Index Questionnaire 343840 and four subscales (symptoms, activities of daily living, function in sport and recreation) of the KOOS. ${ }^{45} 46$

\section{Psychological factors}

Eighteen different instruments were used to measure psychological constructs, the results of which are presented under four construct groupings; mental health, cognitive factors, behavioural factors and other psychological factors (table 2). Mental health included measures of depression, anxiety and general mental health. ${ }^{51}$ In line with previously used cognitive and behavioural groupings, ${ }^{52}$

cognitive factors were coping strategies and catastrophising, whereas behavioural factors were dependency, fear of movement (kinesiophobia) and fear avoidance. Other psychological factors include measures of emotional well-being and social aspects that did not fit within the other factor groupings.

The most commonly used psychological measure was the Short Form-36 health survey Mental Health Component (SF-36 MHC). ${ }^{26-28} 31-3540434950$ Other instruments measuring constructs of mental health that were used more than once include the EuroQol-5 Dimensions Anxiety/Depression Subscale 38414546 and the Hospital Anxiety and Depression Scale..$^{29} 30$

Instruments measuring cognitive factors that were used more than once were the Pain Catastrophising Scale 293046 and the Coping Strategies Questionnaire. ${ }^{29}{ }^{30}$ Fear-Avoidance Beliefs Questionnaire $^{363739}$ and the Tampa Scale of Kinesiophobia 293033 
were the instruments measuring behavioural factors used more than once.

\section{Psychological characteristics of people with PFP (aim 1)}

Meta-analysis was not possible because of heterogeneity of the included studies. Twenty studies reported data from PFP cohorts without asymptomatic comparator groups. These data are presented in online supplementary file 3 and are supported by online supplementary files 4 and 5 . The following narrative synthesis focuses on data obtained from the five case-control studies, which enables comparison between PFP and controls (aim 1). It also highlights results from single-group studies investigating correlations between PFP and psychological factors.

\section{Mental health}

General mental health, measured with the SF-36 MHC (vitality, social function, role emotional and mental health sub-scales) was significantly lower in a group of adults with PFP (SMD 1.21; 95\% CI 0.81 to 1.62 ) (Q3). ${ }^{27}$

Anxiety and/or depression was compared with pain-free controls in three studies. Hopkins Symptom Checklist- 25 scores revealed significantly higher levels for one adult group with PFP (SMD 1.03 ; 95\% CI 0.43 to 1.64$)(\mathrm{Q} 3)^{48}$ but no significant differences between-group scores across the different Karolinska scales of personality in a separate study (Q1). ${ }^{47}$ In the case where only frequency data were available, a group of adolescents with PFP had 3.00 (95\% CI 0.34 to 26.45) times the risk of anxiety/ depression than controls (Q4). ${ }^{46}$

\section{Cognitive factors}

Several coping strategies demonstrated significant betweengroup differences. One student cohort with PFP group found it harder to divert their attention (SMD 0.40; 95\% CI 0.02 to 0.82 ) than those who were PFP free (Q3). ${ }^{44}$ In a different student cohort, levels of catastrophising were significantly higher in those with PFP (SMD 1.07; 95\% CI 0.41 to 1.74 ) (Q4). ${ }^{46}$

\section{Behavioural factors}

Levels of dependency, measured with Carlsson's Dependency Scale were not significantly different between those with and without PFP (SMD 0.10; 95\% CI -0.57 to 0.78 ) (Q1). ${ }^{47}$

\section{Personality and other psychosocial factors}

All studies in this section had pain-free comparators. No significant differences were found between PFP and pain-free group scores of the Schalling-Sifneos Alexithymia Scale-Revised (SMD 0.24 ; $95 \%$ CI -0.44 to 0.91 ) (Q1). ${ }^{47}$ Stress, measured with Carlsson's Stress Scale, was significantly higher in a group of adults with PFP (SMD 0.72; 95\% CI 0.03 to 1.42 ) (Q1). ${ }^{47}$ From the Coop Wonca Chart subscale, adults with PFP reported experiencing significantly more emotional problems (SMD 0.89; 95\% CI 0.30 to 1.49 ) than PFP-free controls (Q3). ${ }^{48}$

\section{Correlation between psychological factors, PFP and physical function (aim 2) \\ Mental health}

Small to medium correlations (ranging from $r=0.13$ to $r=0.47$ ) were found between all sub-scales of the SF-36 MHC and the Thai (Q1), ${ }^{26}$ Chinese (Q1) ${ }^{28}$ and Persian (Q2) ${ }^{35}$ versions of the Kujala Patellofemoral Scale. The SF-36 sub-scales of 'social function' and 'mental health' both demonstrated small correlations with the Functional Index questionnaire, $r=0.23$ and $\mathrm{r}=0.15$, respectively $(\mathrm{Q} 3) \cdot{ }^{34}$ All SF-36 subscales apart from role emotional $(r=0.08)$ demonstrated small correlations with the Modified Functional Index Questionnaire (Q3). ${ }^{34}$

When measured with the Beck Anxiety Inventory (Q4) ${ }^{36}$ and the Hospital Anxiety and Depression Scale (Q2), ${ }^{30}$ anxiety was correlated with pain $(r=0.34$ and $r=0.46$, respectively) and with physical function $(r=0.45$ and $r=0.57$, respectively). Depression was also correlated with pain $(r=0.44)$ and physical function $(r=-0.61)(\mathrm{Q} 2) .{ }^{30}$ When measured over a 6-month period, improvement change scores in pain and physical function were associated with changes in anxiety $(r=0.41$ and $r=0.43$, respectively) and depression $(r=0.54$ and $r=0.59$, respectively) (Q2). ${ }^{29}$

\section{Cognitive factors}

Catastrophising and the coping strategy of 'praying and hoping' both correlated to pain $(\mathrm{r}=0.43$ and $\mathrm{r}=0.35$, respectively) and physical function $\left(\mathrm{r}=-0.53\right.$ and $\mathrm{r}=-0.38$, respectively) (Q2)..$^{30}$ When measured over a 6-month period, improvement change scores in pain and physical function were correlated with reduced catastrophising $\left(r=0.59\right.$ and $r=0.57$, respectively) $(\mathrm{Q} 2) .^{29}$

\section{Behavioural factors}

Fear of movement (Q2) ${ }^{30}$ and the fear-avoidance beliefs relating to physical activity (FABQ-PA) and work (FABQ-W) (Q4) ${ }^{36}$ were all associated with pain $(r=0.26, r=0.31$ and $r=0.37$, respectively) and physical function $(r=0.26, r=0.31$ and $r=0.37$, respectively). When measured over a 2 -month follow-up period, pain reductions and physical functional improvements were associated with reduced FABQ-PA scores $(r=0.51$ and $r=0.57$, respectively). But only pain reductions were associated with reduced FABQ-W scores $(r=0.30)(\mathrm{Q} 4) .{ }^{37}$

\section{DISCUSSION}

This systematic review identified psychological characteristics that differed between individuals with PFP and asymptomatic controls in several cohorts. Further, according to our second aim, we found linear correlations between some psychological characteristics and measures of pain and physical function in individuals with PFP.

\section{Psychological characteristics in individuals with PFP}

Four case-control studies report evidence of abnormal psychological features in those with PFP. Specifically, general mental health was worse; ${ }^{27}$ adolescents catastrophised more that PFP-free counterparts; ${ }^{46}$ and an active group employed different coping strategies. ${ }^{44}$ Other results suggestive of elevated scores on tests of psychological features were: high levels of fear avoidance in $26 \%$ of an adolescent cohort; ${ }^{39}$ levels of anxiety/depression in Danish adolescents $(12 \%-15 \%)^{46}$ above that reported in normative data for Danish school-aged children $(8.8 \%) ;{ }^{53}$ and a study from the $\mathrm{UK}^{38}$ reporting a greater prevalence of anxiety/ depressive symptoms (26\%) than that recorded for the general population by the Office of National Statistics (19\%). ${ }^{54}$

Several studies reported no evidence of elevated non-physical characteristics in PFP. One case-control study found no difference in levels of anxiety/depression between groups with and without PFP. ${ }^{47}$ Single-group studies also reported mean anxiety and depression levels that were not abnormal; ${ }^{42}$ mean anxiety and depression levels ${ }^{41}$ below that of a national normative dataset; ${ }^{55}$ and SF-36 MHC results that, when compared with normative equivalents, demonstrate normal mental health in individuals with PFP. 26283435 


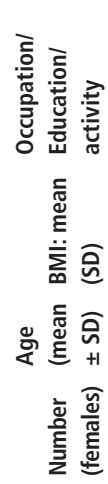

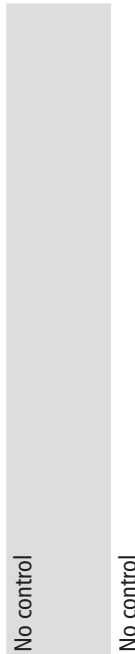

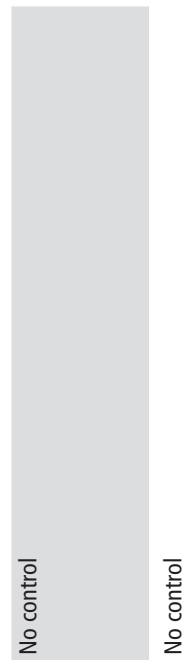

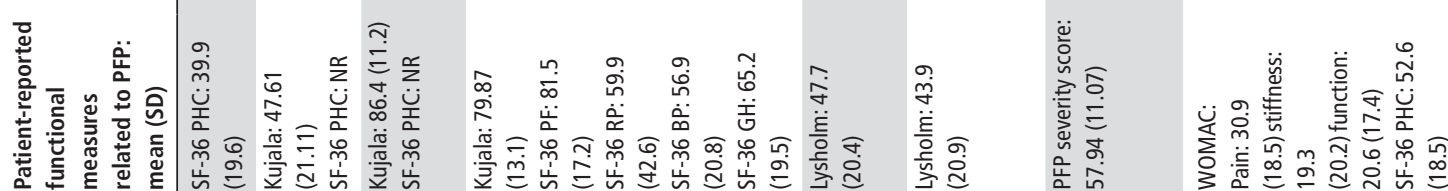

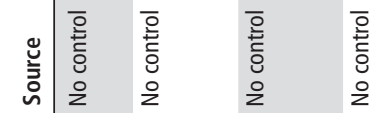

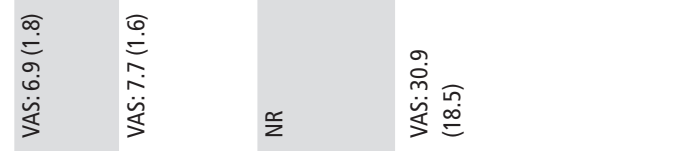

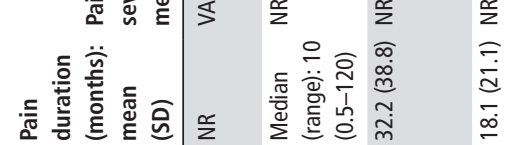

$\simeq$

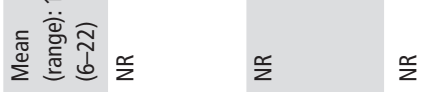

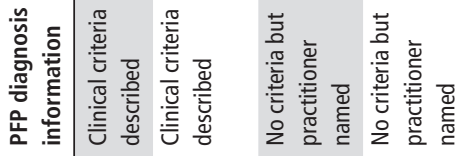

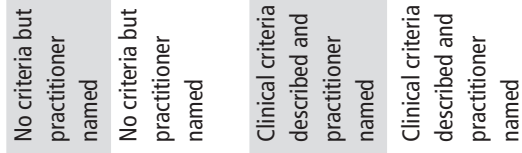

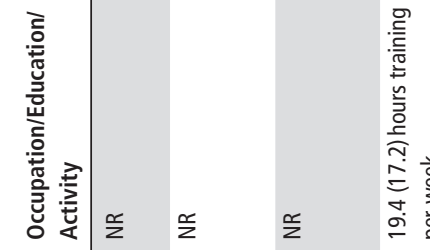

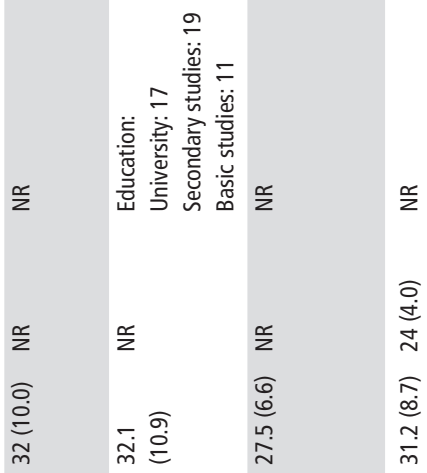

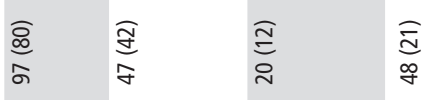

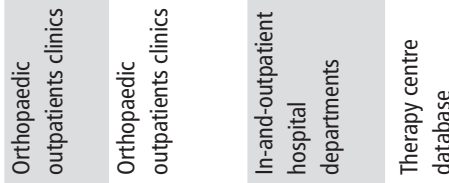

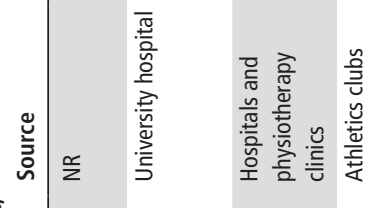

安菜

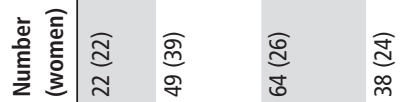

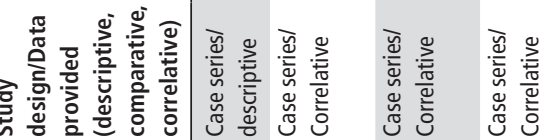

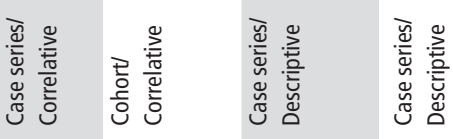

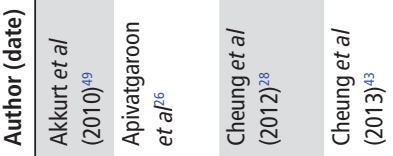

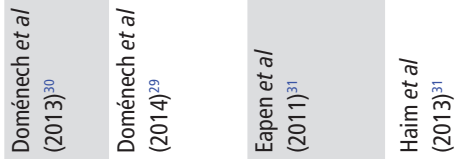




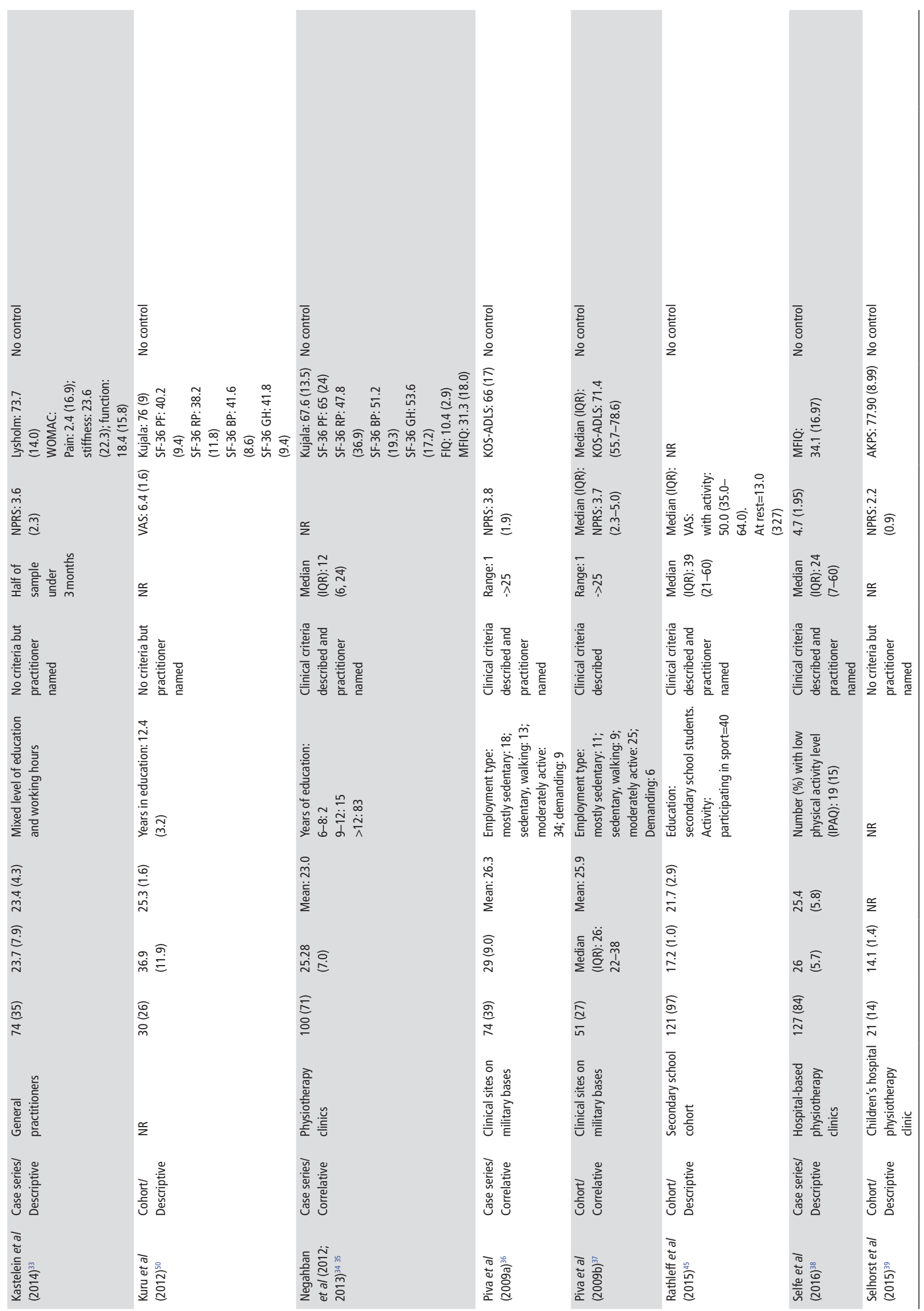




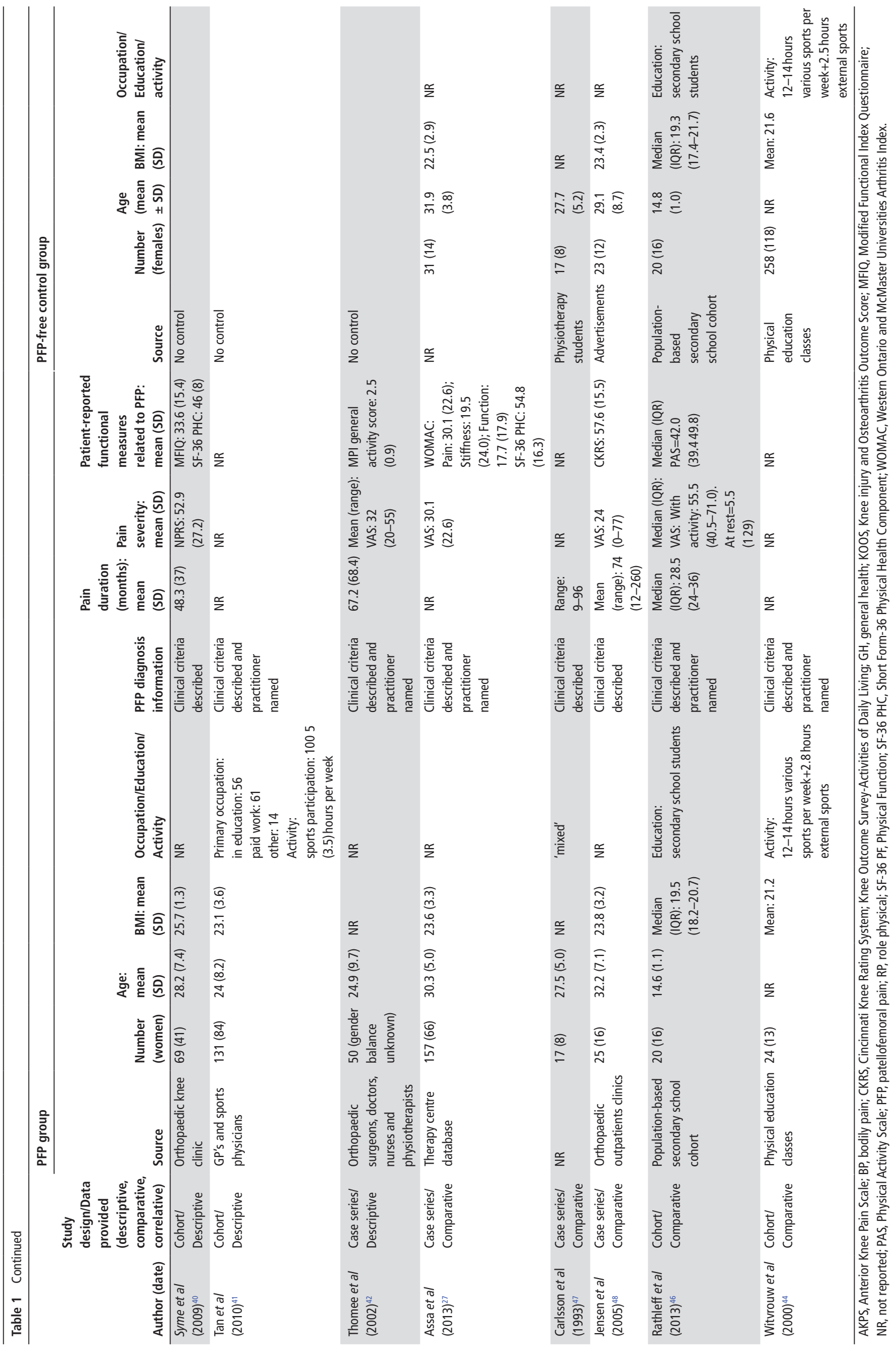


Table 2 Outcome measures presented within their allocated construct groupings. Information about the measure and who it was used by. Further information is provided in online supplementary file 2.

\begin{tabular}{|c|c|c|c|c|}
\hline Instrument & Constructs evaluated & Number of items; subscales & Score interpretation & Used by \\
\hline \multicolumn{5}{|l|}{ Mental health measures } \\
\hline $\begin{array}{l}\text { 36-Item Short Form Health } \\
\text { Survey Mental Health } \\
\text { Component }^{72}\end{array}$ & $\begin{array}{l}\text { Generic mental health } \\
\text { measure }\end{array}$ & $\begin{array}{l}14 \text { items; four subscales (vitality; social functioning; } \\
\text { role emotional; mental health) }\end{array}$ & $\begin{array}{l}\text { Each subscale } 0-100 . \text { Higher score }= \\
\text { better mental health }\end{array}$ & $\begin{array}{l}24,46,23,25 \\
40,28,29,30 \\
47,31,32,37\end{array}$ \\
\hline EuroQol—-5 Dimensions 3 Level $^{73}$ & $\begin{array}{l}\text { Generic quality of life } \\
\text { measure }\end{array}$ & $\begin{array}{l}\text { Five items; five subscales (only one related to mental } \\
\text { health; anxiety/ depression) Three-level version: no } \\
\text { problems; moderate problems; extreme problems. } \\
\text { Five-level version: no problems; slight problems; } \\
\text { moderate problems; severe problems; extreme } \\
\text { problems. }\end{array}$ & & $43,42,35,38$ \\
\hline $\begin{array}{l}\text { Hospital Anxiety and Depression } \\
\text { Scale }^{74}\end{array}$ & Anxiety and depression & 14 items; two subscales (anxiety and depression) & $\begin{array}{l}\text { Each subscale } 0-21 \\
0-7=\text { non-case } \\
8-10=\text { possible case } \\
>10=\text { probable case }\end{array}$ & 27,26 \\
\hline $\begin{array}{l}\text { Modified Karolinska Scales of } \\
\text { Personality }{ }^{75}\end{array}$ & $\begin{array}{l}\text { Version featured in } \\
\text { this review focused on } \\
\text { anxiety }\end{array}$ & $\begin{array}{l}10 \text { scales (psychic anxiety; psychasthenia; low } \\
\text { assertiveness; somatic anxiety; muscular tension; } \\
\text { indirect aggression; verbal aggression; irritability; } \\
\text { suspicion; guilt }\end{array}$ & Unable to determine & 44 \\
\hline $\begin{array}{l}\text { Hopkins Symptom Checklist - } 25 \\
\text { items }^{76}\end{array}$ & Mental distress & 25 items; two = anxiety and depression & $\begin{array}{l}\text { Each item } 1=\text { not at all, to } 4=\text { extremely } \\
\text { Average score }(1.00-4.00) \text { calculated }\end{array}$ & 45 \\
\hline Beck Anxiety Inventory ${ }^{77}$ & Anxiety & 21 items & $\begin{array}{l}\text { Each item 0-3 giving overall score } 0-63 \\
\text { Higher scores mean more anxiety }\end{array}$ & 33 \\
\hline $\begin{array}{l}\text { Spielberger State Trait Anxiety } \\
\text { Inventory }{ }^{78}\end{array}$ & Anxiety & $\begin{array}{l}40 \text { items; two = current state of anxiety (S-anxiety). } \\
\text { Stable, trait aspect of anxiety (T-anxiety) }\end{array}$ & $\begin{array}{l}\text { Each item 1-4 } \\
\text { Scores added with higher scores } \\
\text { indicating greater anxiety }\end{array}$ & 39 \\
\hline \multicolumn{5}{|l|}{ Cognitive measures } \\
\hline Pain Catastrophising Scale ${ }^{79}$ & Catastrophising & $\begin{array}{l}13 \text { items; three subscales (rumination, magnification } \\
\text { and helplessness) }\end{array}$ & $\begin{array}{l}\text { Each item } 0=\text { not at all, to } 4=\text { all the } \\
\text { time } \\
\text { Higher overall score means higher levels } \\
\text { of catastrophising }\end{array}$ & $27,26,43$ \\
\hline $\begin{array}{l}\text { Coping Strategies } \\
\text { Questionnaire }^{80}\end{array}$ & Coping strategies & $\begin{array}{l}48 \text { items; eight subscales (diverting attention, } \\
\text { reinterpreting pain sensations, catastrophising, } \\
\text { ignoring sensations, praying and hoping, coping } \\
\text { self-statements, increased behaviour activities) }\end{array}$ & $\begin{array}{l}\text { Each item } 0=\text { no control, to } 6= \\
\text { complete control }\end{array}$ & $27,26,39$ \\
\hline Utrecht Coping List ${ }^{81}$ & Coping strategies & $\begin{array}{l}44 \text { items; seven subscales (active tackling, seeking } \\
\text { social support, palliative reacting, avoiding, passive } \\
\text { reacting, reassuring thoughts, expression of emotions }\end{array}$ & Unable to determine & 41 \\
\hline $\begin{array}{l}\text { Amsterdam Biographic } \\
\text { Questionnaire }^{82}\end{array}$ & Unable to determine & Unable to determine & Unable to determine & 41 \\
\hline \multicolumn{5}{|l|}{ Behavioural measures } \\
\hline Tampa Scale of Kinesiophobia ${ }^{71}$ & Fear of movement & 17 items & $\begin{array}{l}\text { Each item } 0 \text { to } 4 \\
\text { Higher net score }=\text { increased fear of } \\
\text { movement }\end{array}$ & $27,26,30$ \\
\hline $\begin{array}{l}\text { Fear-Avoidance Beliefs } \\
\text { Questionnaire }^{83}\end{array}$ & Fear-avoidance beliefs & 16 items; two subscales (physical activity and work) & $\begin{array}{l}\text { Each item } 0 \text { to } 6 \\
\text { Higher net score }=\text { increased fear- } \\
\text { avoidance beliefs }\end{array}$ & $33,34,36$ \\
\hline Carlsson's Dependency Scale ${ }^{47}$ & Dependency & No instrument information available & & 44 \\
\hline \multicolumn{5}{|l|}{ Other related measures } \\
\hline Coop-Wonca Chart ${ }^{84}$ & $\begin{array}{l}\text { Generic quality of life } \\
\text { measure }\end{array}$ & $\begin{array}{l}\text { Six items; only one related to psychological function } \\
\text { (feelings) }\end{array}$ & $\begin{array}{l}1 \text { to } 5 \\
\text { Higher score = more emotional } \\
\text { problems }\end{array}$ & 45,30 \\
\hline $\begin{array}{l}\text { Schalling-Sifneos Alexithymia } \\
\text { Scale }^{85}\end{array}$ & Alexithymia & 20 items & Each item answered yes or no & 44 \\
\hline Carlsson's Stress Scale ${ }^{47}$ & Stress & No instrument information available & & 44 \\
\hline $\begin{array}{l}\text { WHO Disability Assessment } \\
\text { Schedule } 2.0^{86}\end{array}$ & $\begin{array}{l}\text { Overall function } \\
\text { (psychological and } \\
\text { physical) }\end{array}$ & $\begin{array}{l}12 \text { items; } 6 \text { domains. } 1 \text { directly related to } \\
\text { psychological function (cognition) }\end{array}$ & $\begin{array}{l}\text { Each item } 0 \text { to } 4 \\
\text { Higher score = more difficulty }\end{array}$ & 35 \\
\hline
\end{tabular}


In summary, there were four case-control studies that found psychological differences between PFP and control participants, compared with one that did not. The four studies that found differences were in the higher quality rating (Q3; $;^{27} 48$ $\left.\mathrm{Q} 4^{46}\right)$ while the one that found no change rated poorly $\left(\mathrm{Q} 1^{47}\right)$. Supporting comparative data were three high-rating single-group studies $\left(\mathrm{Q} 3 ;^{37}{ }^{38} \mathrm{Q} 4^{45}\right)$,demonstrating elevated psychological factors compared with six single-group studies that found no difference in measures. Of the latter, four rated poorly (Q1;26 2842 $\mathrm{Q} 2^{35}$ ) and two rated highly $\left.\mathrm{Q} 3 ;^{34} \mathrm{Q} 4^{41}\right)$. Thus, many of these findings suggest that coping strategies including catastrophising may differ in those with PFP, though the clinical relevance of the size of this difference is yet to be determined. Findings also suggest that anxiety/depression and fear avoidance may be elevated, especially in adolescents. These results derive from a disparate group of studies that use a wide variety of psychological measures. Sample sizes were, for the most part, small, which may explain why some studies failed to find evidence of abnormal non-physical features. The small samples also prevent accurate estimation of the prevalence of non-physical features in PFP.

\section{Correlation between psychological factors, PFP and physical function}

This review revealed several non-physical features that are correlated with PFP in a linear manner. As single mental health constructs, anxiety and depression demonstrated moderate-tolarge correlation with pain and physical function. ${ }^{29} 303637$ All studies that used the SF-36 MHC only evaluated relationships with physical function and all found small-to-moderate correlations at best. ${ }^{26} 283435$

Beyond mental health, catastrophising ${ }^{29} 30$ and pain-related fear ${ }^{29} 303637$ were the cognitive and behavioural factors, respectively, that demonstrated the strongest and most consistent correlation with both pain and physical function. Catastrophising and fear avoidance beliefs have previously been described as the cognitive and behavioural determinants of the pain experience. ${ }^{56}$ It remains unknown whether the experience of pain and the inability to perform physical tasks lead to the development of psychological problems, or whether psychological features influence pain and function through mechanisms such as effects on endogenous pain modulation, individual resilience and the motivation needed to cope with the symptoms of PFP. Longitudinal research is required to study these potential temporal relationships.

\section{Comparison with non-physical characteristics in other knee conditions}

A number of systematic reviews have explored the relationship between psychological factors and short-, medium- and long-term postoperative pain following total knee arthroplasty. The psychological factors identified therein included catastrophising, ${ }^{57-61}$ depression ${ }^{58-60}$ and anxiety. ${ }^{60}$ In other knee conditions, psychological factors also seem to share a relationship with function. Higher levels of exercise adherence, higher perceived rehabilitation effort and greater rates of home exercise completion have been found in patients with greater general self-efficacy following ACL reconstruction. ${ }^{62}$ Recognising the similarities in psychological factors between these knee conditions and PFP provide support for consideration of non-physical factors in addition to mechanically focused PFP management strategies.

\section{Implications for clinicians who are managing PFP}

PFP and low back pain (LBP) are similar from several perspectives. Both conditions can stem from insidious roots, limit physical function and persist. In both instances, the cause of pain can be hard to define and the pathway from acute pain to chronicity poorly understood. They differ in terms of structure, anatomical region and depth of investigation of involvement of psychological features of the conditions. Drawing from LBP research, subgroups that demonstrate the highest levels of psychological impairment are those with the highest pain intensities, the greatest disability and the longest pain duration. ${ }^{63-65}$ Psychological factors also act as significant barriers to home exercise programme adherence, ${ }^{66}$ influence the transition from persistent to chronic widespread pain $^{67}$ and increase healthcare usage. ${ }^{68} 69$

Facing a growing literature base implicating non-physical features in the development and maintenance of persistent musculoskeletal pain, clinicians who assess and treat PFP should screen for their presence. Generic instruments, such as the shortform Orebro Musculoskeletal Pain Questionnaire, ${ }^{70}$ are simple to implement and can be completed early in the consultation process. If further investigation is merited, concise assessment of individual psychological constructs can be conducted using the instruments highlighted in this review (eg, fear of movement with the Tampa Scale of Kinesiophobia). ${ }^{71}$

\section{Future research}

The identification of differences in psychological factors between individuals with PFP and controls, as well as relationships with pain and physical function, suggests that there might be subgroups of PFP that require different treatment approaches. Three studies in this review attempted to subgroup participants. One took a cross-sectional approach to identify physical phenotypes $^{38}$ and one identified a range of physical measures that may be potential risk factors for PFP development. ${ }^{44}$ The third applied a treatment algorithm that first identified and directed treatment according to the results of a fear-avoidance beliefs assessment. ${ }^{39}$ In the latter, a comparator group receiving usual care was lacking, but tailored treatment produced clinically significant physical functional improvements (Anterior Knee Pain Scale scores) for $100 \%$ of participants and clinically significant reductions in pain severity for 33\%. Although the potential benefits of subgrouping people with PFP to guide treatment remain relatively unknown, these results provide a stimulus for further studies. This includes further comparison of psychological factors between those with and without PFP, psychometric evaluation of psychological measures used in PFP groups and consistent use of recommended measures.

\section{Strengths and limitations}

This review has attempted to address the complex topic of non-physical features of PFP. The overall results are derived, in many cases, from a disparate group of studies without PFP-free comparators that were too diverse for data pooling. The wide range of psychological measures used also made the compiling and comparing of the results challenging. For most studies, investigation of psychological factors was not a primary aim, and this reflects in the generally low EAI quality ratings. The wide range of study designs made selection of an appropriate quality appraisal tool difficult. While comprehensive enough to evaluate the range of studies in this review (cohort and case series), the EAI did not evaluate the quality of specific study design analyses. The potential to define, classify and select 
psychological measures for analysis also proved challenging and needs consideration when drawing inferences from the findings.

\section{Key messages}

\section{What is already known on this subject?}

- Patellofemoral pain (PFP) is a highly prevalent musculoskeletal condition that can be challenging to manage.

- PFP is usually considered in a biomechanical paradigm.

- Non-physical, psychological factors are increasingly recognised for their role in other persistent musculoskeletal pain conditions.

\section{What are the new findings?}

- Some mental health and cognitive profiles were different in those with PFP compared with asymptomatic controls.

- A range of mental health, cognitive and behavioural factors were correlated with pain and physical function.

- Few studies have compared psychological profiles between those with and without PFP, and none have used the same measure.

\section{CONCLUSION}

This systematic review has demonstrated that anxiety, depression, catastrophising and pain-related fear may be elevated in individuals with PFP. It has also identified linear correlation between PFP-related symptoms and psychological factors such as catastrophising and pain-related fear. These findings are derived from studies with relatively small sample sizes, few of which included healthy control groups for comparison. Large case-control studies are needed to confirm the presence and prevalence of non-physical features.

Contributors $\mathrm{LM}$ and $\mathrm{MM}$ were responsible for the systematic search and data extraction. LM and NC were responsible for the methodological quality appraisals. All authors were involved in the study design, drafting and manuscript editing.

\section{Competing interests None declared.}

Provenance and peer review Not commissioned; externally peer reviewed.

(c) Article author(s) (or their employer(s) unless otherwise stated in the text of the article) 2017. All rights reserved. No commercial use is permitted unless otherwise expressly granted.

\section{REFERENCES}

1 Boling M, Padua D, Marshall S, et al. Gender differences in the incidence and prevalence of patellofemoral pain syndrome. Scand I Med Sci Sports 2010;20:725-30

2 Witvrouw E, Callaghan MJ, Stefanik JJ, et al. Patellofemoral pain: consensus statement from the 3rd international Patellofemoral Pain Research Retreat held in Vancouver, September 2013. Br J Sports Med 2014;48:411-4.

3 Cook C, Mabry L, Reiman MP, et al. Best tests/clinical findings for screening and diagnosis of patellofemoral pain syndrome: a systematic review. Physiotherapy 2012;98:93-100.

4 Nunes GS, Stapait EL, Kirsten MH, et al. Clinical test for diagnosis of patellofemoral pain syndrome: Systematic review with meta-analysis. Phys Ther Sport 2013:14:54-9.

5 Rathleff MS, Vicenzino B, Middelkoop M, et al. Patellofemoral pain in adolescence and adulthood: same same, but different? Sports Med 2015;45:1489-95.

6 Nimon G, Murray D, Sandow M, et al. Natural history of anterior knee pain: a 14- to 20-year follow-up of nonoperative management. J Pediatr Orthop 1998;18:118-22.

7 Crossley KM, van Middelkoop M, Callaghan MJ, et al. Patellofemoral pain consensus statement from the 4th international patellofemoral pain research retreat, Manchester. Part 2: recommended physical interventions (exercise, taping, bracing, foot orthoses and combined interventions). Br J Sports Med 2016. Published Online First: 31 May 2016.
8 Collins NJ, Bierma-Zeinstra SM, Crossley KM, et al. Prognostic factors for patellofemoral pain: a multicentre observational analysis. Br J Sports Med 2013:47:227-33.

9 Lankhorst NE, van Middelkoop M, Crossley KM, et al. Factors that predict a poor outcome 5-8 years after the diagnosis of patellofemoral pain: a multicentre observational analysis. Br J Sports Med 2016;50:881-6.

10 Crossley KM, Stefanik JJ, Selfe J, et al. 2016 patellofemoral pain consensus statement from the 4th international Patellofemoral Pain Research Retreat, Manchester. Part 1: Terminology, definitions, clinical examination, natural history, patellofemoral osteoarthritis and patient-reported outcome measures. Br J Sports Med 2016:50:839-43.

11 Carroll LJ, Cassidy JD, Côté P. Depression as a risk factor for onset of an episode of troublesome neck and low back pain. Pain 2004;107:134-9.

12 Crombez G, Vlaeyen JW, Heuts PH, et al. Pain-related fear is more disabling than pain itself: evidence on the role of pain-related fear in chronic back pain disability. Pain 1999;80:329-39.

13 Grotle M, Foster NE, Dunn KM, et al. Are prognostic indicators for poor outcome different for acute and chronic low back pain consulters in primary care? Pain 2010;151:790-7.

14 Henschke N, Maher CG, Refshauge KM, et al. Prognosis in patients with recent onset low back pain in australian primary care: inception cohort study. BMJ 2008;337:a171. http://www.ncbi.nlm.nih.gov/pmc/articles/PMC2483884/pdf/bmj. a171.pdf (accessed 10 Dec 2008).

15 Sullivan MJL, Adams H, Thibault P, et al. Initial depression severity and the trajectory of recovery following cognitive-behavioral intervention for work disability. J Occup Rehabil 2006;16:60-71.

16 Beneciuk JM, George SZ. Pragmatic implementation of a stratified primary care model for low back pain management in outpatient physical therapy settings: twophase, sequential preliminary study. Phys Ther 2015;95:1120-34.

17 Bergbom S, Flink IK, Boersma K, et al. Early psychologically informed interventions for workers at risk for pain-related disability: does matching treatment to profile improve outcome? J Occup Rehabil 2014;24:446-57.

18 Hill JC, Fritz JM. Psychosocial influences on low back pain, disability, and response to treatment. Phys Ther 2011;91:712-21.

19 Main CJ, George SZ. Psychologically informed practice for management of low back pain: future directions in practice and research. Phys Ther 2011;91:820-4.

20 Sandow MJ, Goodfellow JW. The natural history of anterior knee pain in adolescents. J Bone Joint Surg Br 1985;67:36-8.

21 Moher D, Liberati A, Tetzlaff J, et al; PRISMA Group. Preferred reporting items for systematic reviews and meta-analyses: the PRISMA statement. Ann Intern Med 2009;151:264-9.

22 Genaidy AM, Lemasters GK, Lockey J, et al. An epidemiological appraisal instrument - a tool for evaluation of epidemiological studies. Ergonomics 2007;50:920-60.

23 World Health Organization. Risk to mental health: an overview of vulnerabilities and risk factors. plan sftdoacmha. Geneva: WHO, 2012.

24 Landis JR, Koch GG. The measurement of observer agreement for categorical data. Biometrics 1977;33:159-74.

25 Cohen J. A power primer. Psychol Bull 1992;112:155-9.

26 Apivatgaroon A, Angthong C, Sanguanjit P, et al. The validity and reliability of the thai version of the Kujala score for patients with patellofemoral pain syndrome. Disabil Rehabil 2016;38:2161-4. http://www.tandfonline.com/doi/abs/ (accessed 13 Jan 2016).

27 Assa T, Elbaz A, Mor A, et al. Gait metric profile of 157 patients suffering from anterior knee pain. A controlled study. Knee 2013;20:40-4

28 Cheung RT, Ngai SP, Lam PL, et al. Chinese translation and validation of the Kujala scale for patients with patellofemoral pain. Disabil Rehabil 2012;34:510-3.

29 Doménech J, Sanchis-Alfonso V, Espejo B. Changes in Catastrophizing and kinesiophobia are predictive of changes in disability and pain after treatment in patients with anterior knee pain. Knee Surg Sports Traumatol Arthrosc 2014;22:2295-300.

30 Domenech J, Sanchis-Alfonso V, López L, et al. Influence of kinesiophobia and catastrophizing on pain and disability in anterior knee pain patients. Knee Surg Sports Traumatol Arthrosc 2013;21:1562-8.

31 Eapen C, Nayak CD, Pazhyaottyil Zulfeequer C. Effect of eccentric isotonic quadriceps muscle exercises on patellofemoral pain syndrome: an exploratory pilot study. Asian J Sports Med 2011:2:227-34.

32 Haim A, Segal G, Elbaz A, et al. The outcome of a novel biomechanical therapy for patients suffering from anterior knee pain. Knee 2013;20:595-9.

33 Kastelein M, Luijsterburg PA, Heintjes EM, et al. The 6-year trajectory of nontraumatic knee symptoms (including patellofemoral pain) in adolescents and 
young adults in general practice: a study of clinical predictors. Br J Sports Med 2015;49:400-5.

34 Negahban H, Pouretezad M, Sohani SM, et al. Validation of the persian version of functional index questionnaire (FIQ) and Modified FIQ in patients with patellofemoral pain syndrome. Physiother Theory Pract 2013;29:521-30.

35 Negahban H, Pouretezad M, Yazdi MJS, et al. Persian translation and validation of the kujala patellofemoral scale in patients with patellofemoral pain syndrome. Disabil Rehabil 2012;34:2259-63.

36 Piva SR, Fitzgerald GK, Irrgang JJ, et al. Associates of physical function and pain in patients with patellofemoral pain syndrome. Arch Phys Med Rehabil 2009;90:285-95

37 Piva SR, Fitzgerald GK, Wisniewski S, et al. Predictors of pain and function outcome after rehabilitation in patients with patellofemoral pain syndrome. J Rehabil Med 2009:41:604-12.

38 Selfe J, Janssen J, Callaghan M, et al. Are there three main subgroups within the patellofemoral pain population? A detailed characterisation study of 127 patients to help develop targeted intervention (TIPPs). Br J Sports Med 2016;50:873-80. http:// www.ncbi.nlm.nih.gov/pubmed/26834185 (accessed 16 Feb 2016).

39 Selhorst M, Rice W, Degenhart T, et al. Evaluation of a treatment algorithm for patients with patellofemoral pain syndrome: a pilot study. Int I Sports Phys Ther 2015:10:178-88.

40 Syme G, Rowe P, Martin D, et al. Disability in patients with chronic patellofemoral pain syndrome: a randomised controlled trial of VMO selective training versus general quadriceps strengthening. Man Ther 2009;14:252-63.

41 Tan SS, van Linschoten RL, van Middelkoop M, et al. Cost-utility of exercise therapy in adolescents and young adults suffering from the patellofemoral pain syndrome. Scand J Med Sci Sports 2010;20:568-79.

42 Thomee P, Thomee R, Karlsson J. Patellofemoral pain syndrome: pain, coping strategies and degree of well-being. Scand J Med Sci Sports 2002;12:276-81.

43 Cheung RTH, Zhang Z, Ngai SPC. Different relationships between the level of patellofemoral pain and quality of life in professional and amateur athletes. $P M \& R$ 2013:5:568-72.

44 Witvrouw E, Lysens R, Bellemans J, et al. Intrinsic risk factors for the development of anterior knee pain in an athletic population. A two-year prospective study. Am J Sports Med 2000;28:480-9.

45 Rathleff MS, Roos EM, Olesen JL, et al. Exercise during school hours when added to patient education improves outcome for 2 years in adolescent patellofemoral pain: a cluster randomised trial. Br J Sports Med 2015;49:406-12.

46 Rathleff CR, Baird WN, Olesen JL, et al. Hip and knee strength is not affected in 1216 year old adolescents with patellofemoral pain-a cross-sectional population-based study. PLoS One 2013;8:e79153.

47 Carlsson AM, Werner S, Mattlar CE, et al. Personality in patients with long-term patellofemoral pain syndrome. Knee Surg Sports Traumatol Arthrosc 1993;1:178-83.

48 Jensen R, Hystad T, Baerheim A. Knee function and pain related to psychological variables in patients with long-term patellofemoral pain syndrome. J Orthop Sports Phys Ther 2005;35:594-600.

49 Akkurt E, Salli A, Ozerbil OM, et al. The effect of isokinetic exercise on symptoms, functional status and EMG activation onset time of the vastus medialis oblique and vastus lateralis in female patients with patellofemoral pain syndrome. Isokinet Ex Sc 2010;18:157-61.

50 Kuru T, Yalıman A, Dereli EE. Comparison of efficiency of Kinesio $®$ taping and electrical stimulation in patients with patellofemoral pain syndrome. Acta Orthop Traumatol Turc 2012;46:385-92.

51 Phyomaung PP, Dubowitz J, Cicuttini FM, et al. Are depression, anxiety and poor mental health risk factors for knee pain? A systematic review. BMC Musculoskelet Disord 2014;15:10.

52 Urquhart DM, Phyomaung PP, Dubowitz J, et al. Are cognitive and behavioural factors associated with knee pain? A systematic review. Semin Arthritis Rheum 2015;44:445-55

53 Leth I, Niclasen J, Ryding E, et al. Psychological difficulties among children and adolescents with ethnic danish, Immigrant, and Refugee Backgrounds. Scand J Child Adolesc Psychiatr Psychol 2014;2:29-37.

54 Beaumont J, Lofts H. Measuring National Well-being - Health 2013. London. Office for National Statistics 2013.

55 Penninx BW, Beekman AT, Smit JH, et al; NESDA Research Consortium. The Netherlands Study of Depression and Anxiety (NESDA): rationale, objectives and methods. Int J Methods Psychiatr Res 2008;17:121-40.

56 Sullivan MJ, Thorn B, Haythornthwaite JA, et al. Theoretical perspectives on the relation between catastrophizing and pain. Clin J Pain 2001;17:52-64.

57 Burns LC, Ritvo SE, Ferguson MK, et al. Pain catastrophizing as a risk factor for chronic pain after total knee arthroplasty: a systematic review. J Pain Res 2015:8:21-32.
58 Drosos GI, Triantafilidou T, Ververidis A, et al. Persistent post-surgical pain and neuropathic pain after total knee replacement. World J Orthop 2015;6:528-36.

59 Lewis GN, Rice DA, McNair PJ, et al. Predictors of persistent pain after total knee arthroplasty: a systematic review and meta-analysis. Br J Anaesth 2015;114:551-61.

60 Lungu E, Vendittoli PA, Desmeules F. Preoperative determinants of patient-reported pain and physical function levels following total knee arthroplasty: a systematic review. Open Orthop J 2016;10:213-31.

61 Vissers MM, Bussmann JB, Verhaar JA, et al. Psychological factors affecting the outcome of total hip and knee arthroplasty: a systematic review. Semin Arthritis Rheum 2012:41:576-88.

62 Everhart JS, Best TM, Flanigan DC. Psychological predictors of anterior cruciate ligament reconstruction outcomes: a systematic review. Knee Surg Sports Traumatol Arthrosc 2015:23:752-62.

63 Beneciuk JM, Robinson ME, George SZ. Subgrouping for patients with low back pain: a multidimensional approach incorporating cluster analysis and the STarT back screening Tool. J Pain 2015;16:19-30.

64 Pinheiro MB, Ferreira ML, Refshauge K, et al. Symptoms of depression as a prognostic factor for low back pain: a systematic review. Spine J 2016;16:105-16.

65 Rabey M, Smith A, Beales D, et al. Differing psychologically derived clusters in people with chronic low back pain are associated with different multidimensional profiles. Clin J Pain 2016;2016; . http://bit.ly/29FRXp8 (accessed 14 Apr 2016).

66 Palazzo C, Klinger E, Dorner V, et al. Barriers to home-based exercise program adherence with chronic low back pain: Patient expectations regarding new technologies. Ann Phys Rehabil Med 2016:59:107-13.

67 Viniol A, Jegan N, Brugger M, et al. Even worse - risk factors and protective factors for transition from chronic localized low back pain to chronic widespread pain in general practice: a cohort study. Spine 2015;40:E890-E899.

68 Hirsch 0 , Strauch K, Held H, et al. Low back pain patient subgroups in primary care: pain characteristics, psychosocial determinants, and health care utilization. Clin $J$ Pain 2014;30:1023-32.

69 Traeger AC, Hübscher M, Henschke N, et al. Emotional distress drives health services overuse in patients with acute low back pain: a longitudinal observational study. Eur Spine J 2016;25:2767-73. http://link.springer.com/article/10.1007\%2Fs00586-016 4461-0 (accessed 14 Apr 2016)

70 Linton SJ, Nicholas M, MacDonald S. Development of a short form of the örebro musculoskeletal pain screening questionnaire. Spine 2011;36:1891-5.

71 Miller RP, Kori S, Todd D. The Tampa Scale: a measure of kinesiophobia. Clin J Pain $1991 ; 7: 51-2$

72 Ware JE, Sherbourne CD. The MOS 36-item short-form health survey (SF-36). I. Conceptual framework and item selection. Med Care 1992;30:473-83.

73 The EuroQol Group. EuroQol-a new facility for the measurement of health-related quality of life. Health Policy 1990;16:53-72.

74 Zigmond AS, Snaith RP. The hospital anxiety and depression scale. Acta Psychiatr Scand 1983:67:361-70.

75 Schalling D. In: The trait-situation interaction and the physiological correlates of behavior. Endler DMN, ed. Personality at the crossroads; Current issues in interactional psychology. Hillsdale, NJ: Lawrence Erlbaum Associates, 1977:129-41.

76 Parloff MB, Kelman HC, Frank JD. Comfort, effectiveness, and self-awareness as criteria of improvement in psychotherapy. Am J Psychiatry 1954;111:343-52.

77 Beck AT, Epstein N, Brown G, et al. An inventory for measuring clinical anxiety: Psychometric properties. J Consult Clin Psychol 1988;56:893-7.

78 Spielberger CD, Gorsuch RL, Lushene R, et al. Manual for the State-Trait Anxiety Inventory. Palo Alto, CA: Consulting Psychologists Press, 1983.

79 Sullivan MJL, Bishop SR, Pivik J. The pain catastrophizing scale: Development and validation. Psychol Assess 1995:7:524-32.

80 Rosenstiel AK, Keefe FJ. The use of coping strategies in chronic low back pain patients: relationship to patient characteristics and current adjustment. Pain 1983; 17:33-44

81 Schreurs PJG, van de Willige G, Tellegen B, et al. Herziene handleiding utrechtse coping lijst (UCL). Lisse:Swets \& Zeitlinger BV 1993.

82 van Engelen LA. Questionnaires in selection situations. norms of the $A B Q$ (Amsterdam Biographical Questionnaire) and the AMT (Achievement Motivation Test) for selection studies]. Ned Tijdschr Psychol 1969:24:682-96.

83 Waddell G, Newton M, Henderson I, et al. A Fear-Avoidance beliefs questionnaire $(F A B Q)$ and the role of fear-avoidance beliefs in chronic low back pain and disability. Pain 1993:52:157-68

84 Committee WC. Functional Status Measurement in Primary Care. New York/Berlin/ Heidelberg: Springer Verlag, 1990.

85 Sifneos PE. The Schalling-Sifneos personality scale revised. Psychother Psychosom 1986:45:161-5.

86 World Health Organisation. Measuring health and disability: manual for WHO disability assessment schedule (WHODAS 2.0). Geneva: WHO, 2010 